\title{
Job Stress and Productivity Increase
}

\author{
Samson Sunday Adaramola \\ Dept of Human Factors/Ergonomics, Vine Tribometric Consultant, Nigeria, West Africa
}

\begin{abstract}
This paper examines mental and physical pressures that workers bear at work. The authors discuss how onthe-job stress affects a person's capabilities and productivity, and how such pressures lend to higher incidences of accidents at work. The paper also discuses methods of reducing job-related stress and increasing productivity.
\end{abstract}

An intervention was conducted amongst workers in a private firm. It shows mental and emotional pressure can affect performance and productivity of a worker on the job. One of the biggest influences of today's worker is onthe-job stress. Job stress occurs when the requirements of the job do not match the capabilities, resources, or needs of the worker. This consequently affects how a person would normally deal with customer service problems, grievances, violence, conflict, and decisions on the job. Stress is an inevitable part of everyday life, and is therefore a distinct part of a person's job. To properly control the outcome of stress, there are certain precautions and methods that should be taken that will boost productivity

Keywords: "Illness"; "Pressure"; "Intervention" "Performance"

\section{Introduction}

What is stress? Taber's cyclopedia Medical Dictionary defines stress as "the result produced when a structure system, or organism is acted upon by forces that disrupt equilibrium or produce strain" In simpler terms, stress is the result of any emotional, physical, social, economic or other factors that require a response or change. It is generally believed that some stress is okay (sometimes referred to as "challenge or positive stress) but when stress occur in amounts that you cannot handle, both mental and physical changes may occur. ${ }^{*}$

"Workplace stress" then is the harmful physical and emotional responses that can happen when there is a conflict between job demands on the employee and the amount of control an employee has over meeting these demands. In general,[1] the combination of

\footnotetext{
${ }^{*}$ Corresponding author. Email: vinetribo@yahoo.com
}

high demands in a job and a low amount of control over the situation can lead to stress

No matter what type of work setting, it's important to pay attention to your stress levels so you are able to implement workplace safety[3].Many times, the reason why stress causes accidents in the workplace is because it causes people to become inattentive to their surroundings. Being aware of your stress levels and how it affects your work safety can help you avoid accidents and injuries.

It is believed that 60 to $80 \%$ of accidents on the job are stress related and some, like the Three Mile Island and Exxon Valdez disasters exemplified this.

\section{Pressure and Performance}

The Inverted $U$ model is applied in this analysis The relationship between pressure and performance is explained in one of the oldest and most important ideas in stress management,[4] the "Inverted-U" relationship between pressure and performance. The 
Inverted-U relationship focuses on people's performance of a task.

The left hand side of the graph is easy to explain for pragmatic reasons. When there is very little pressure on us to carry out an important task, there is little incentive for us to focus energy and attention on it. This is particularly the case when there may be other, more urgent, or more interesting, tasks competing for attention.

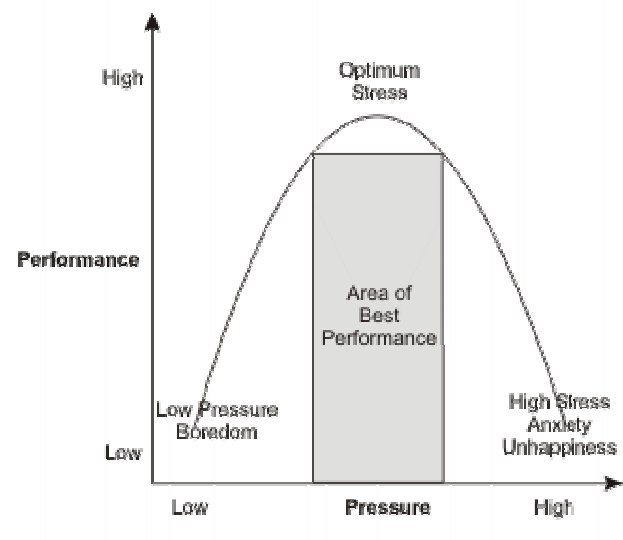

The Inverted-U relationship between pressure and performance

Figure 1: The Inverted U Model

As pressure on us increases, we enter the "area of best performance". Here, we are able to focus on the task and perform well - there is enough pressure on us to focus our attention but not so much that it disrupts our performance.

The right hand side of the graph is more complex to explain.

\section{Results of Intervention in a Private Firm}

Evaluations of varieties of information collected during the problem identification phase of the intervention, includes: information from employees about working conditions, levels of perceived stress, health problems, and satisfaction.[2] Employee perceptions are usually the most sensitive measure of stressful working conditions and often provide the first indication of intervention effectiveness. I added objective measures such as absenteeism and health care costs and found it useful. However, the effects of job stress interventions on such measures tend to be less clear-cut and can take a long time to appear. Corrective measures were applied appropriately depending on the conditions prevalent
After the analysis of the data gathered, the employees were grouped under three conditions:

1) Mild, 2) Intermediate and 3) Severe

Applying the Inverted $U$ model, the following graphical representations were deduced for each group before and after intervention

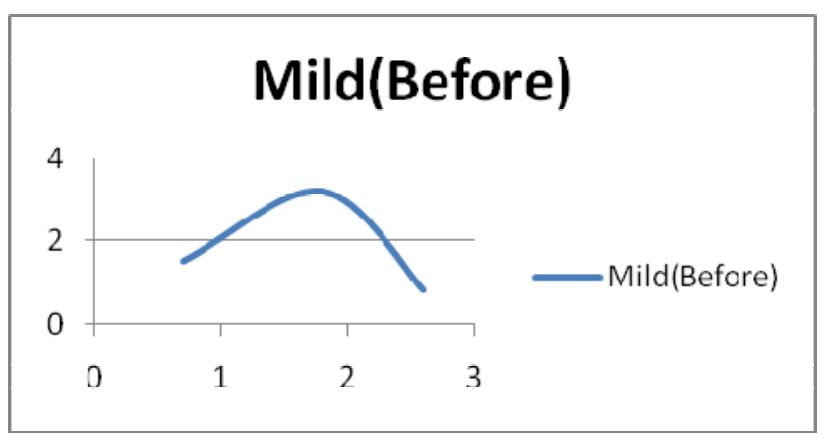

Figure 2: Area of Best Performance (Mild/Before)

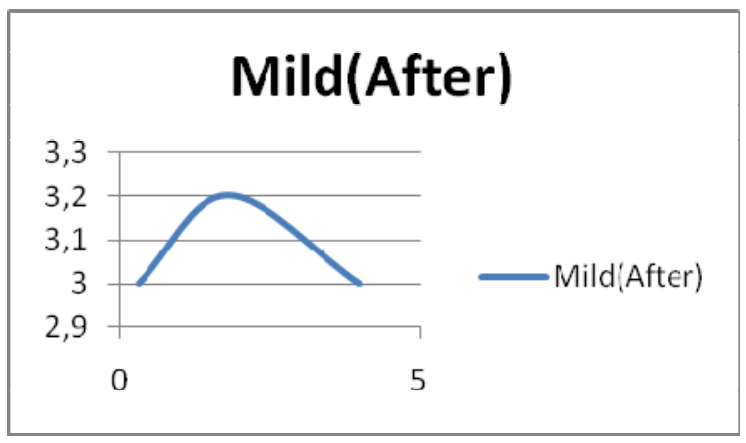

Figure 3: Area of Best Performance (Mild/After)

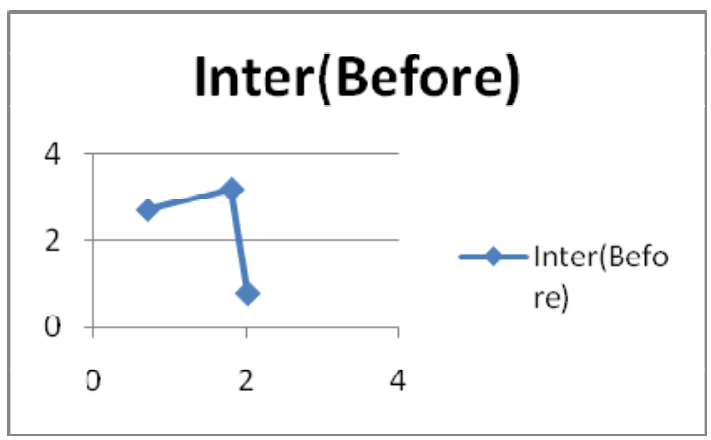

Figure 4: Area of Best Performance (Intermediate/Before) 


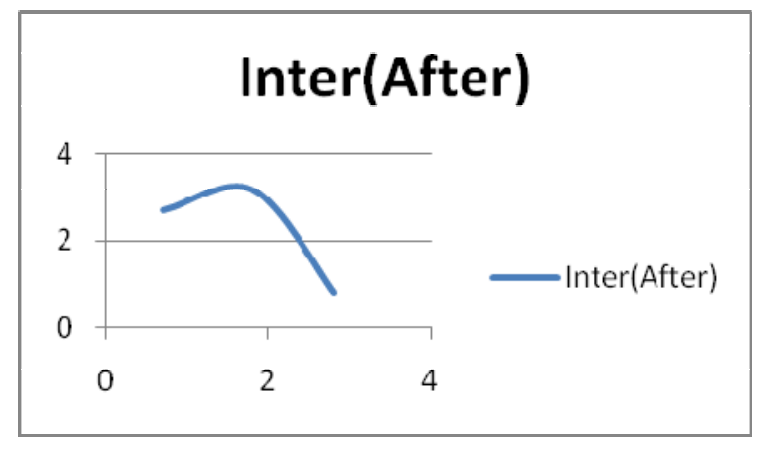

Figure 5: Area of Best Performance (Intermediate/After)

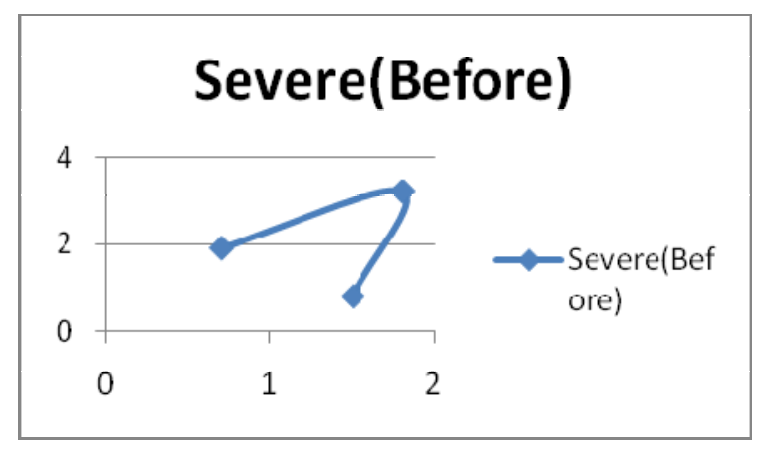

Figure 6: Area of Best Performance (Severe/Before)

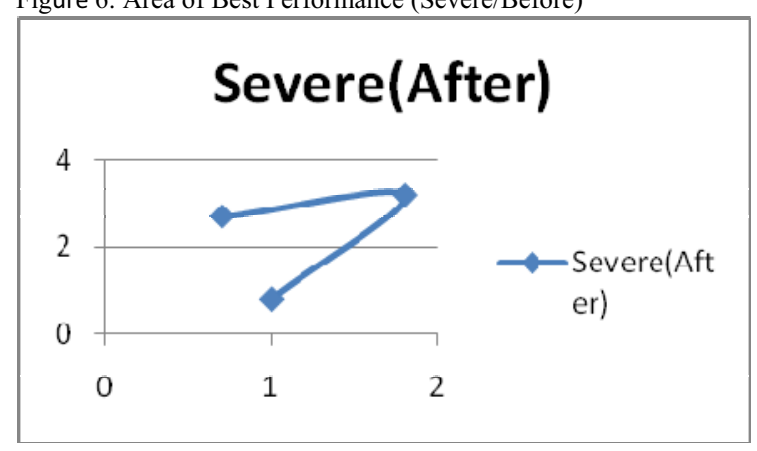

Figure 7: Area of Best Performance (Severe/After) Stress Management

There are three major approaches that can be use to manage stress:

- Action-oriented: In which we seek to confront the problem causing the stress, changing the environment or the situation;

- Emotionally-oriented: In which we do not have the power to change the situation, but we can manage stress by changing our interpretation of the situation and the way we feel about it; and

- Acceptance-oriented: Where something has happened over which we have no power and no emotional control, and where our focus is on surviving the stress.
A) Action-oriented approaches - best where you have some control

To be able to take an action-oriented approach, we must have some power in the situation. If we do, then action-oriented approaches are some of the most satisfying and rewarding ways of managing stress. These are techniques that we can use to manage and overcome stressful situations, changing them to our advantage.

These approaches introduce skills that help you to manage your job actively, work well with your boss and co-workers, and change your surroundings to eliminate environmental stress. The Action-oriented management is:

- Cope with the Stress of Work Overload

- $\quad$ Survive the Stress of Problem Jobs

- Deal With Problem People

- Manage Environmental Stress

- Manage Performance Stress

- Avoid Burnout.

B) Emotionally-oriented approaches - subtle but effective

If you do not have the power to change a situation, then you may be able to reduce stress by changing the way you look at it, using an emotionally-oriented approach.

Emotionally-oriented approaches are often less attractive than action-oriented approaches in that the stresses can recur time and again; however, they are useful and effective in their place.

C) Acceptance-oriented approaches - when there's no valid alternative

Sometimes, we have so little power in a situation that all we can do to survive it. This is the case, for example, when loved-ones die.

\section{Conclusion and Recommendation}

These different approaches to stress management address our definition of stress in different ways: the action-oriented techniques help us to manage the demands upon us and increase the resources we can mobilize; the emotionally oriented techniques help us to adjust our perceptions of the situation; and the acceptance-oriented techniques help us survive the situations that we genuinely cannot change.

\section{References}

[1] Encyclopedia of Occupational Health and Safety. Sauter S, Hurrell J, Murphy L, Levi L [1997]. Psychosocial and organizational factors. In: Stellman J, ed. Encyclopedia of 
Occupational Health and Safety. Vol. 1. Geneva, Switzerland: International Labour Office, pp. 34.1-34.77.

[2] Families and Work Institute Bond JT, Galinsky E, Swanberg JE [1998]. The 1997 national study of the changing workforce. New York, NY: Families and Work Institute.

[3] Journal of Applied Psychology Jones JW, Barge BN, Steffy BD, Fay LM, Kuntz LK, Wuebker LJ [1988]. Stress and medical malpractice: organizational risk assessment and intervention. Journal of Applied Psychology 73(4):727-735.

[4] Stress and Your Performance Article, Mind Tools Ltd 2nd Floor 145-157 St John Street London EC1V 4PY United Kingdom 